\title{
Scaffolding shared imagination with tangible design
}

\author{
Maarten L. Smith \\ Industrial Design, Eindhoven \\ University of Technology, Eindhoven, \\ Netherlands \\ m.l.smith@tue.nl
}

\author{
Sander van der Zwan \\ Industrial Design, Eindhoven \\ University of Technology, Eindhoven, \\ Netherlands \\ s.v.d.zwan@tue.nl
}

\author{
Jelle P. Bruineberg \\ Department of Philosophy, Macquarie \\ University, Sydney, Australia \& \\ Industrial Design, Eindhoven \\ University of Technology, Eindhoven, \\ Netherlands \\ j.bruineberg@gmail.com
}

\author{
Pierre D. Lévy \\ Industrial Design, Eindhoven \\ University of Technology, Eindhoven, \\ Netherlands \\ plevy@tue.nl
}

\author{
Caroline C. M. Hummels \\ Industrial Design, Eindhoven \\ University of Technology, Eindhoven, \\ Netherlands \\ c.c.m.hummels@tue.nl
}

\begin{abstract}
We follow up on a prominent line of work in which principles of embodied cognition are employed to not only account for skilled coping but also for more intellectual activities such as remembering and imagination. Imagination then, is not a reflective activity an individual does by herself, but a shared and embodied activity scaffolded by tangible design. We present a case study in which we designed a toolkit to facilitate imagining the Netherlands in 2050. We wrote speculative stories of people living in 2050 and designed an assortment of objects. We held several workshops to use the toolkit for shared imagination for our client, Rijkswaterstaat. We analyze how, in the context of the workshops, the stories and objects provided affordances for shared imagination. We thereby hope to have demonstrated that it is possible to design for more intellectual activities in a tangible and embodied way.
\end{abstract}

\section{CCS CONCEPTS}

- Human-centered computing; • Interaction design; • Interaction design theory, concepts and paradigms;

\section{KEYWORDS}

Imagination, Affordances, Higher cognition, Embodied interaction

\section{ACM Reference Format:}

Maarten L. Smith, Sander van der Zwan, Jelle P. Bruineberg, Pierre D. Lévy, and Caroline C. M. Hummels. 2021. Scaffolding shared imagination with tangible design. In Fifteenth International Conference on Tangible, Embedded, and Embodied Interaction (TEI '21), February 14-17, 2021, Salzburg, Austria. ACM, New York, NY, USA, 9 pages. https://doi.org/10.1145/3430524.3440639

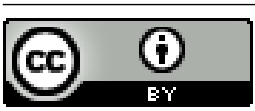

This work is licensed under a Creative Commons Attribution International 4.0 License. TEI '21, February 14-17, 2021, Salzburg, Austria

(C) 2021 Copyright held by the owner/author(s).

ACM ISBN 978-1-4503-8213-7/21/02.

https://doi.org/10.1145/3430524.3440639

\section{INTRODUCTION}

The TEI-community has been successful in promoting skilled, embodied and unreflective coping over a detached reflection-based approach to everyday activities [28]. This is characterized by efforts to reduce semantic pollution, for example by replacing the use of graphical symbols and metaphors with tangible interactions $[6,16]$. These efforts resonate with ecological and enactivist approaches to cognition, which form part of the theoretical backbone of the community [28]. Traditionally, these approaches have been able to deal well with many of our practical everyday activities, in particular what others have characterized as 'lower' cognitive abilities, such as interactions with daily tools, e.g., riding a bike, using a knife and fork and so forth. However, it is often claimed that they fall short when employed to account for 'higher level' cognitive activities such as memory and imagination $[3,4,9]$. As a response to this objection, recent movements in ecological and enactive philosophy have shown that such 'higher level' cognition can often be regarded as a shared and embodied activity [5,27]. For example, an activity like remembering may be scaffolded by the embodied, tangible and social relations a subject has with her environment [13, 19]. The promise these movements in philosophy and cognitive science hold is the possibility for the TEI-community to extend its scope to include what would typically be considered 'higher' cognitive activities, while staying true to its theoretical roots.

In this paper, we pick up on the philosophical claim mentioned above and the accompanying promise to empower designers to not only make products, systems and services that reduce both reflective strain and semantic pollution from our everyday lives, but also co-shape how we imagine, remember and reflect. In particular, we focus on imagination. Imagination, as understood in ecological and enactive terms, is not a merely mental activity individuals do by themselves, but a shared and embodied activity scaffolded by their social and material environment $[5,10]$.

The aim of this design philosophical research is to show a practical example of how designing for imagination can be approached from an ecological and enactive perspective and how the specifics of such a design co-shape the imaginative activity taking place. To do this, we demonstrate and unpack a design project that has 
been undertaken in collaboration with Rijkswaterstaat, the executive agency of the Dutch Ministry of Infrastructure and Water Management.

In the following sections, we begin by addressing the term 'affordance', as it takes center stage in recent movements of ecological and enactive philosophy and has come to be used differently than within design research until now. This is followed by a description of the design project. We then employ ecological and enactivist terms to make sense of the design in use. The inquiry is concluded with a discussion on affording imagination and the consequences of considering imagination as a skilled activity, scaffolded by a social and material environment, for the TEI-community.

\section{SCALING-UP OF AFFORDANCES}

The term affordance was first coined by psychologist James Gibson [11], who defined affordances as possibilities for action provided by the environment to the organism, such as grasping, touching and walking. From there it has made its way into, among others, the field of design, psychology and philosophy, often with a slightly altered definition fit for the specific explanatory purposes.

\subsection{Affordances in design as proposed by Donald Norman}

In design and human-computer interaction, Donald Norman picked up on the term in his book The Psychology of Everyday Things (POET) [21] and developed it further in later articles [22, 23]. For Norman, we need to clearly distinguish between what he calls real affordances, perceived affordances, constraints and conventions.

Real affordances are action possibilities provided by the environment that exist whether the organism perceives them or not, while, of course, the perceived ones are being perceived. More than a decade after POET, Norman adds that, on top of affordances, products have constraints. He gives the example of moving a mouse across the screen and being constrained by the physicality of the screen to move it outside of its borders. The final concept he distinguishes is a convention. A convention isn't an affordance either, rather it is something that is culturally learned [22]. He gives the example of the scroll-bar on a webpage. The fact that you should click and drag the graphic on the right side of the screen to see what is below, is a culturally learned convention [22].

In short, what the product really affords is different from what humans perceive to be afforded. Affordances in general are accompanied by constraints. Constraints are aspects of the product, of the acting individual or of convention (i.e., culturally learned ways of doing things) that withhold and encourage the individual to undertake certain actions.

\subsection{Affordances in ecological and enactive philosophy}

In contrast to Norman's notion of affordances, recent movements in ecological and enactive philosophy have led to an account of affordances with a much broader application than motor possibilities. In this account, affordances are situated in the context of a form of life, they are skill-dependent and can be perceived as relevant. Let's take a look at these concepts in more detail.
2.2.1 Form of life. 'Form of life' (Lebensform), is a term used by Wittgenstein to emphasize that activities are embedded in practices. It foregrounds humanity's historical practice, i.e., we do not only share our biology with other human beings, but also our sociocultural practices, our stable ways of living. It is the bedrock on which Wittgenstein's inquiry into human activities stands. From it follows that the meaning of a linguistic utterance, or any other action, depends on its use, which is context dependent. Meaning is thus not inherent in particular signs or symbols, but tied to social practice.

The ecological and enactivist approach borrows this term to emphasize that human affordances come forth from, and are embedded in the practices in which they make sense. They are not relative to a particular individual's actual engagement with them, but rather to the practice as a whole. In other words, they are relative to a practice in which individuals have a potential to detect them [25]. For example, a first-year design student might not know what a laser cutter is, nor might he have the skills to use it. The affordance of using the laser cutter does however exist independent of this student, because it is being enacted in the design practice as a whole.

The notion that affordances are embedded in a form of life allows the ecological and enactive approach to argue that the enactment of affordances involves a basic level of normativity, or "situated normativity" [24]. We can distinguish from better or worse ways of doing things based both on concrete material settings as well as on whether or not they are in agreement with what members of a practice do. For example, as the student starts engaging with the laser cutter, the performance is typically corrected by a teacher or fellow student and might be normatively assessed as part of formal design education.

2.2.2 Skills and ability. There is a diverse variety of practices and so many different forms of life. While there are important differences between practices, there are often also important commonalities. The ecological and enactivist account of affordances maintains that much of the variation in forms of life (and thus practices) can be attributed to variation in skills $[15,25]$. Skills, in this case, are not just techniques of the body but "the capabilities of action and perception of the whole organic being (indissolubly mind and body) situated in a richly structured environment." [15]. To continue the aforementioned example, as the student progresses in her studies, a skilled practitioner might show her the laser cutter, what it does and which buttons to push when. The skilled practitioner might point towards subtle aspects of the environment that are relevant when using the machine such as the line thickness in the illustrator file, the colors of those lines and the type of material used. By pointing out these cues and practicing with the machine, the student learns to perceive the relevant affordances that are part of using the machine. Using the laser cutter becomes not only an affordance in the design practice as a whole, but a potentially relevant affordance for the student as well. In this sense, the affordances are not separate from skills or conventions, but intermeshed with them.

To be clear, according to enactive theory, whether or not affordances are provided by the environment is not merely dependent on the physical or digital nature of the things involved, but also on the skills that exist and are developed within a specific cultural practice. 
From this perspective the distinctions between real and perceived affordances or between conventions and affordances seem to disappear. The enactive use of the word affordances does not neglect the worries Norman had when writing about the aforementioned distinctions, but rather looks for the answers on a different shelf. ${ }^{1}$

2.2.3 Relevance. The aforementioned conceptual tools help us distinguish between affordances in a practice and affordances as they show up for acting individuals. Another helpful tool provided by the ecological and enactivist approach is that of relevance or 'solicitation' $[2,25]$. While an environment offers a multitude of affordances at any given time, only some of those show up as relevant. This relevance is relative to our abilities (or skills) and our dynamically changing concerns, i.e., our needs, preferences and interests. For example, the affordance of using the laser cutter might show up as relevant to the student while being concerned with the production of a prototype. To be a skilled user of the laser cutter is to be solicited by the relevant affordances in the specific context and thereby to be sensitive to the demands of the situation [2].

\subsection{Summary: Affordances and intellectual activity}

These developments point to a different use of affordances in design and TEI. As mentioned before, traditionally a clear distinction has been made between 'higher' and 'lower' level cognitive activities. This distinction was also central to Hubert Dreyfus's distinction between skillful coping and detached thinking [7]. Dreyfus' account presupposes a sharp distinction between the skilled designer being involved in using the machine without reflection, and the design student, due to some hick-up in the process, detaching herself from the situation of using the laser cutter and reflecting on the appropriate steps to take. These activities have therefore been described as two separate types of activities not belonging to the same realm: affordances pertain to the former, not to the latter.

This sharp distinction has come under pressure as a result of the recent movements in ecological and enactive philosophy. Rather than giving in to the latter distinction, these movements build on a continuity between skilled engagement and reflection. In successful cases of skilled action, reflection becomes part of our everyday coping with the world and detached thinking itself a situated activity [20]. What follows from this analysis is that the use of our intellectual and conceptual abilities (including reflecting, remembering and imagining) is just as context-sensitive and situation-dependent as the use of any other skills. In other words, our intellectual and conceptual abilities are themselves skills that are shared, embodied and scaffolded by our social and material environment [17, 20]. Following this line of thinking empowers designers bent on embodiment and tangibility to design for situations that afford these activities.

\section{IMAGINATION IN DESIGN RESEARCH}

We pay special attention to imagination, for it plays an important role in design practice and research. Besides being an inherent part of the design process, imagination can be something we can work

\footnotetext{
${ }^{1}$ This paragraph merely points to the differences between Norman and the develop ments in ecological and enactive cognition. A conceptual analysis of both concepts of affordances is beyond the scope of this paper.
}

towards. Design researchers have explored a variety of approaches where imagination is a desired outcome, such as speculative design [8], embodied imagination [12] and the use of metaphor [1, 18].

A speculative design approach entails designing objects that could exist in possible futures. The goal here is not a commercial product, but rather a questioning and opening up of future possibilities. Speculative design "thrives on imagination and aims to open up new perspectives on what are sometimes called wicked problems, to create spaces for discussion and debate about alternative ways of being, and to inspire and encourage people's imaginations to flow freely." [8]. When following the embodied imagination method, participants engage non-functional objects in their everyday lives and are prompted to 'speak from their bodies', making them performers in their own lives [12]. Other methods employ metaphor, for example as a generative tool to imagine future technologies and ways of being [18], or as the bridge between our embodied experience and imaginative capacities, resulting in the use of embodied metaphors in design for reasoned imagination [1].

In most of these approaches, the notion of imagination is left implicit. Where made explicit, it is characterized as a cognitive process only happening 'in the head', as in the case of embodied metaphors. A design can trigger such imaginative processes, but is not itself part of the process. This is in contrast with the ecological and enactive view that imagination is a shared and embodied activity scaffolded by a social and material environment [5]. On this view, the design is shaped by and is itself scaffolding the imaginative process. This would allow the TEI-community to extend its scope towards designing for imagination while keeping consistent with its theoretical roots.

The enactive and ecological take on imagination has already been further explicated in philosophical practice [5], however it is both still in development and remains uptil now disconnected from design literature. By demonstrating and analyzing a practical example in which we design for imaginative activity, we hope to not only show how design for imagination can be approached from an ecological and enactive departure point but also contribute to the enactive and ecological account of imagination.

\section{DESIGN CASE: POSSIBLE FUTURES OF THE NETHERLANDS}

In order to get a better understanding of how designing for imagination can be approached from an ecological and enactive perspective, we will analyze a concrete design project entitled Expedition RWS 2050. In this project Rijkswaterstaat aims to imagine a range of possible futures, so that it is better prepared to anticipate and deal with the changing situation in the Netherlands. The leading members of Expedition RWS 2050 (called the "the strategic explorers") do so by gathering insights on these possible futures from different perspectives. As part of this project, they invited us, the Transforming Practices group at the Department of Industrial Design at the Eindhoven University of Technology to use on our design research skills to facilitate discussions with a cross-section of the Dutch population, in order to imagine what the future could possibly look like and what it would mean for them. To facilitate these imaginative discussions, we wrote seven short speculative stories and designed a set of physical discussion tools. 


\subsection{Short stories}

The strategic explorers requested that the discussions be based on a number of demographic, economic, political, socio-cultural and technological trends. In several pilot tests, it quickly became clear that it is difficult for participants to imagine with or relate to these trends. In order to deal with this, we weaved the trends into seven short 'stories from the future', each portraying possible experiences of people living in 2050. By weaving these trends into our stories of everyday experience, we aimed to make participants relate to and reflect on these trends without confronting them with the typical scientific-technological jargon in which these trends were written. Moreover, by re-writing the trends into stories of ordinary life, we aimed to replace the dissociated, objective, engineering perspective on the future by a lived, subjective human perspective that participants could identify with. To further the accessibility of the stories, we recorded them as 'audiobooks' and accompanied them with a visual to strengthen the mood in which the stories were written.

For example, one of these stories, 'Marcel orders lasagna', takes place in a future where the housing situation in the Netherlands has changed to accommodate for a wide variety of different family types, and the government works together with the private sector to improve the population's health using artificial intelligence. The story follows a single man in his late thirties who tries to order a microwave-lasagna online, but is prohibited from completing his order because the supermarket AI has calculated that regularly consuming this meal is dangerously unhealthy for him in particular. $\mathrm{He}$ is offered other alternatives instead and reminded that he will be able to order microwave-lasagna next week again. The stories can be accessed at ExpeditieRWS2050 [26].

\subsection{Discussion tools}

For the strategic explorers, it was important to encourage participatory sensemaking between the carefully selected participants, who were arranged in small groups based on characteristics such as volunteers, promising youngsters, comfortable retired and economically unstable. All the participants at the table were invited to sketch out their imagined future together and share their imagination. To do this, we provided a playing-field and a collection of diverse objects, some recognizable, such as wooden figurines, others more abstract and without a predefined meaning (see Figure 1). After the participants listened to one of the seven stories, the interviewers placed pictures in the middle of the playing field, representing the main characters of the story. The participants were then asked to pick a wooden figure, representing themselves, and place it somewhere on the table in relation to these characters. After this, the interviewers guided them through a joint imaginative discussion. Throughout these discussions, the interviewers traced relevant aspects that were talked about by placing physical objects and post-its on the table (see Figure 2). By actively probing the conversations towards frictions in the participants' values, we aimed to explore the richness of possible stances towards the anticipated futures, based on the participants' backgrounds and diversity and ambiguity of their values [14]. The discussion was wrapped up by asking the participants to state the three most relevant elements of the discussion to them.
We facilitated a total of seven discussions, each around 90 minutes in duration and featuring two to three participants. The participants were selected by Rijkswaterstaat and included people ranging from 23 to 65 years old with diverse backgrounds. All the discussions were conducted in Dutch, the mother tongue of all the participants. In each session, participants with a common background were selected. For example, in one of the sessions, the participants were all retired, and in another, they all worked high-end jobs. These discussions were recorded on video and audio.

\section{SHOWCASING SHARED IMAGINATION}

In order to get to a better understanding of how this imaginative process proceeded, we highlight a few clear examples of how the particularities of the stories and discussion tools co-shape the imaginative activity taking place. The sessions were facilitated by interviewers I1 and I2. In each of these sessions three people participated. We will refer to them as P1, P2 and P3.

\subsection{First example - Session two}

In the following example, participants have just finished listening to a story in which a young boy, on holiday in the Netherlands, finds himself in juvenile court after unknowingly vandalizing a nature reserve. The story explores the possibility of giving parts of nature the same legal rights as humans. The participants have in front of them the playing field, in which placeholders for three characters from the story have been placed. They are then given a figure that stands in for themselves and asked to place this figure in the playing field so that it relates to the characters from the story. In part one, we show an answer to this request, given by one of the participants.

\subsubsection{Part one.}

P3: I could be his mother on the one side, and on the other his schoolteacher, so I hear that this happened to someone. Also we, in our occupation (secondary school teacher), sometimes have to deal with situations where something happens to children and because of that they land in a situation that they'd rather not be in. And then the court is quite far away, but it is realistic. So that's why I put myself in between (the boy and the judge), and then for now ignoring what is happening. So purely on the relation.

Some time passes and a discussion follows in which the relation between the participants and the main characters of the story is played with so that the participants come into agreement with each other.

\subsubsection{Part two.}

P1: I think that judge has to go that way right? She (P3) actually stands between the judge and Kojo. He (the judge) is of course on the other side. Because, why did you put it like this and not the other way round?

I1: Sorry... the?

P3: Well, you could of course put it like this, but you could also turn him (the boy) around, in the sense that I am close to him, and that I am, so to speak, the buffer between him and 


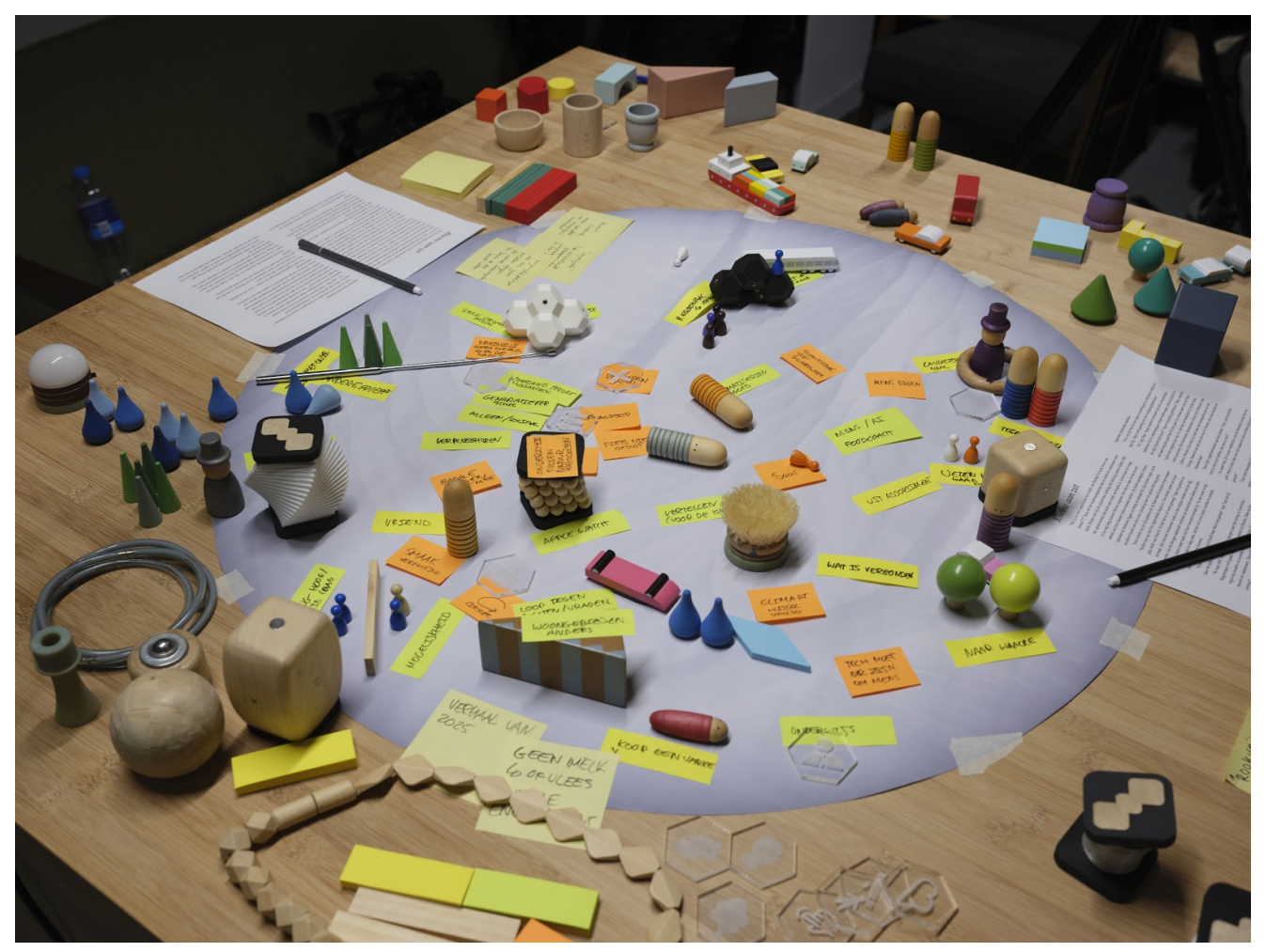

Figure 1: Traces left on the table after one of the sessions.

the children, like what do you tell and what don't you tell But also then...

P3: [Points to two places on the playing field, to which I1 responds and swaps the objects on the table that stand in for P3, the judge and the boy]

P3: Like that yes!

5.1.3 Unpacking the example. Here, the short story affords relating to trends from a first-person perspective. The stories were written with the intent to concretize some of the trends as provided by Rijkswaterstaat. Concretizing here means bringing the trends in relation to human subjectivity, i.e., how a person in 2050 might relate to a world that revolves around a specific trend. After listening to the story, we placed the main character of the story in the middle of the playing field and asked the participants to pick a wooden figure representing themselves, put it somewhere on the playing field, relative to the main character, and explain their chosen position. In placing themselves in the playing field, they were given concrete tools to imagine themselves as living in the described world of 2050 . In other words, the story, the playing field and the wooden figure, afforded them to relate themselves to the described world in 2050 from a first-person perspective. Further, we see that participants can show "directed discontent" [20] to find agreement with one another about the imagined relations. P1 immediately notices that there is something not right about the placement of the stand-ins. P3 points towards the two places, and I1 responds by swapping them.

\subsection{Second example - Session two}

This example follows from the same short story as the previous one. In this segment, I1, I2, P1 and P2 remark that currently areas of the Netherlands are being made into highly protected nature reserves and discuss how we should deal with protecting nature in 2050 .

\subsubsection{Part one.}

P2: I think that these are very separate. That we, so to speak, create a nature reserve and say: here there are very strict rules. But that doesn't mean that that's the case in the other parts of nature. The rest of the world can possibly be very polluting to the environment, but we have made this nature reserve.

I1: [Puts a tube around a few trees on the playing field]

I1: So here you have this, but actually outside of it there's trees and who knows, all sorts of other things. A lot of other things that don't get this (protection). And that's odd.

I1: [Places more trees outside the tube]

P2: Yeah, yeah.

I1: And would you rather have that they are the same?

P2: [Looks directly at I1 and then takes a look at the playing field and laughs]

P2: No, that's impossible. Then you arrive back at the question about harmony between humanity and nature perhaps?

P2: [Touches the tube] 


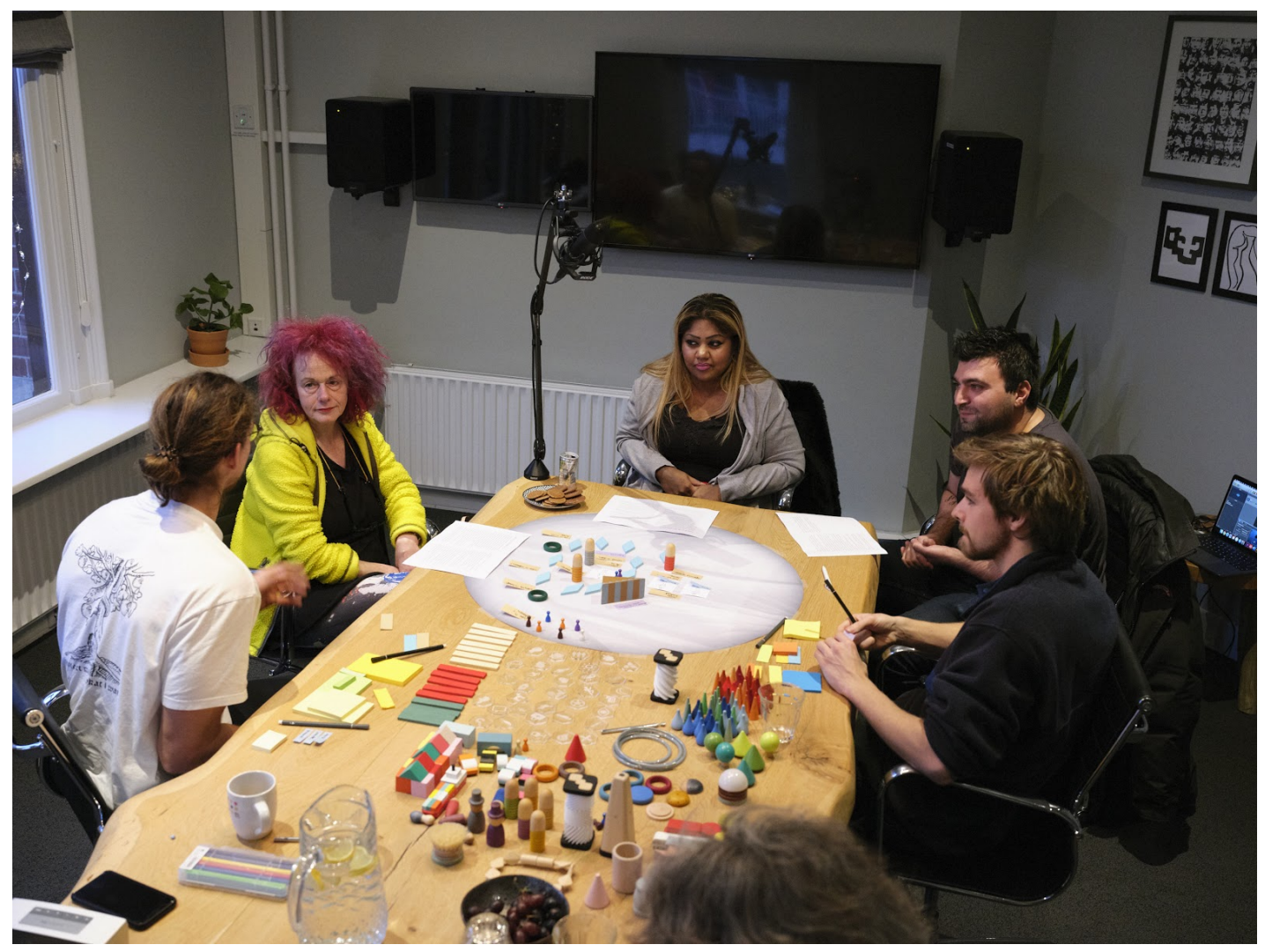

Figure 2: One of the sessions on possible futures of The Netherlands in 2050.

P2: Because, as soon as this is surrounding that, it is also in principle not in harmony.

P2: [Points out that two seperate parts have been created]

P2: You get a kind of partition.

Further on in this session, participants question the situation on the playing field and imagine preferable alternatives.

\subsubsection{Part two.}

P1: Yes, have a look in... ehm ... In this scenario [points to the playing field] we take for granted that there are strict nature reserves that will be surveilled by a civil servant or something like that. But I am more interested in a scenario where we don't have any nature reserves at all anymore. And that is where I'd preferably like to go. That could be 2050 for me.

I2: That's cool, so what does the world look like in that case? We don't have any nature reserves anymore. At this moment in time we do have reserves in the Netherlands. What has changed for that to be the case? What are we then going to do?

P1: Firstly, there needs to be more nature.

I2: By ehm... and where does there need to be more?

P1: The countryside.

I1: Instead of the farmers, so the farmers leave.
I1,2: [Swap the object standing in for grain for trees and green objects]

I2: That was first grain.

I1: Yes, and now it is green. P1 Yes, and at the same, the Randstad ... I don't see it happening that everything is going to become densely populated. I see increasingly that everything will be on one patch, and that we will focus on that. So we will put quality of living in a concentrated area.

I1: Ok, so all the [places a few houses and an apartment building on the middle of the playing field]

I2: So you really get... Do you then also mean that there will be a much bigger patch where nobody lives and where there is also more place for nature?

P2: What I kind of hope, is that there is more nature in the cities. You see that that is often taken away in cities of course, but in the meanwhile, research has been done that shows that it's actually very good for the city. Air quality, atmosphere for people... flooding, those kinds of things.

I2: But that also doesn't come without consequences, here are then...

P1: But I don't think you can call that nature. I agree completely right, but it's about, so to speak, the comfort of living that gets improved if you (live) in kind of a natural... or green 


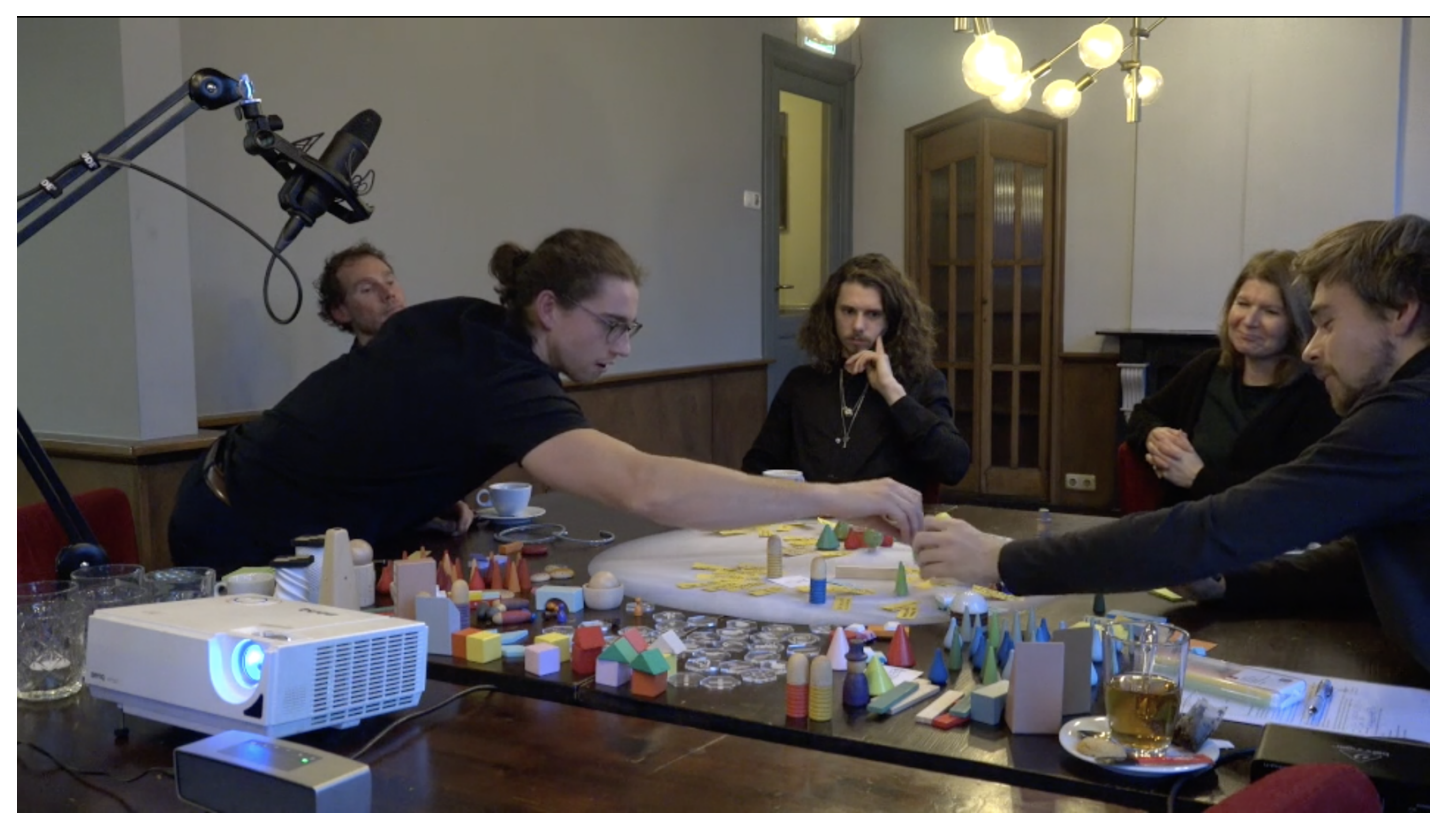

Figure 3: Moving the objects on the table in accord with the conversation

surroundings, let's call it green. And ehm... Yes, maybe a little bit like in the way that the Danish live right ... Then you have Copenhagen, which is and is becoming a fantastic city. And I think that we in the Netherlands, maybe a bit unfortunately, are also going towards. (...) And it isn't realistic to say that we are going to provide everything with a railway connection, so that everyone can go from Groningen to the Randstad, that just isn't going to happen. So, then we will just focus on one area. And there we can go quickly with who knows what kind of shuttle, racing from here to there. And then we can get rid of the car.

5.2.3 Unpacking the example. There are a few things worth noting about this example. We are afforded the possibility to assign meaning to the objects on the table. Some of the objects at our disposal resembled real world counterparts (e.g., trees or cars), others didn't have a 'predefined' meaning. We found that, often, when there were no objects that bore resemblance to what was being talked about, it was a straightforward matter of picking an object and agreeing together that it would stand in for something (Figure 3). In this example, we used an upturned brush to stand in for grain. In another session, we used wooden ladybird figurines to stand in for 3D printers. The only use limit that the objects had in building this world was that they were used as models, they were placeholders of something not present. These objects and placing them on the playing field afforded a few critical actions with regards to imagination. First, they afford the possibility to exclude or include relations from the imagined world in 2050. Second, they afforded summarizing parts of the conversation by pointing to the field. Third, they afforded recalling and remembering of parts of the conversation by looking at the field. Finally, they afforded the interviewers to physically show how they interpreted what has been said by the participants and respond in case of a misunderstanding. In this way, the process of relating to the story and developing a common ground was scaffolded by the material and social settings.

\subsection{Third example - Session six}

This session was introduced with a story about two women sailing an expensive yacht through the flooded streets of the city of Delft. In this segment, I1, I2, P1, P2 and P3 follow up on a discussion about flooding parts of the Netherlands and moving large sections of the population inland.

\subsubsection{Part one.}

P3: That is a part for the government of course... to ehm... put that in motion well and keep an eye on it.

I1: So, I'll put the government in ... let's have a look we'll put it ... so on this little eh... bridge.

I1: [Puts down a man with a top hat on a bridge]

I1: Because they have to be above water somewhere of course.

P3: They've moved to Apeldoorn in the meantime eh?

I1: Ah, exactly, yeah they're all fine there.

I1: What is the task of the government here?

I1: [Points to the bridge with the man in a top hat]

After some time, the discussion moves towards the role the government should play to maintain social cohesion.

\subsubsection{Part two.}

P2: The good things, they aren't glorified, but the negative things are glorified. And that is not good.

P3: Things that don't bring people together, so to speak, that is all glorified, but the other things, that should bring people 
together, those are all ebbing away and... they are hardly there anymore.

(A short discussion about the previous Dutch guilder currency follows)

I1: [Puts the man in the top hat on a podium]

I1: I'll just put ehm... I've raised the government a little bit, right? It gets a bit more power. And it will create a bit of cohesion between all those people, so to speak. So, I'll just put this thing around it.

I1: [Puts down a tube to connect the man with the top hat with figurines that represent society]

I1: Kind of like, we're going to do everything... together.

5.3.3 Unpacking the example. In part 1, P3 mentions that the government should take a role of initiating and evaluating the process of moving the population inland and flooding segments of the Netherlands. I1 traces this and places a stand in for the government on the playing field. In part 2, the participants discuss that the government should actively try to bring people together. The presence of the stand-in placed in the playing field affords I1 the possibility to place it on a higher podium and to stress the government's responsibility to maintain social cohesion by laying down a tube that connects the government with society. The relation between the government and the rest of society is adjusted with regards to the unfolding details of the imagined future.

\section{DISCUSSION: IMAGINATIVE AFFORDANCES}

Looping back to the original design task, Rijkswaterstaat asked us to facilitate a discussion with a cross-section of the Dutch population to imagine what the future could possibly look like and what it would mean for them. The starting point for designing this facilitation were the demographic, economic, political, socio-cultural and technological trends provided by Rijkswaterstaat. Our design, the stories and the discussion table, was a means to make the future relatable from a first-person perspective.

The stories opened a possible future world, but many details were left unspecified. The stories provide a background context which could be referred to during the discussion, but they were written to leave a lot of space open for the participants' imagination to work from. The main characters in the story, which are also present on the playing field, provide a foothold for the participants to imagine themselves in the possible future.

The examples described above show a few imaginative actions that would not have been afforded by reading the trends alone. Stories that involved a main character and her ways of dealing with the trend, made those trends relatable, as was apparent in our first example. The social setting with other participants and interviewers helped to sharpen, refine and renegotiate the process of imagination, as shown between $\mathrm{P} 1$ and $\mathrm{P} 2$ in the second part of example two. The traces of what had been said were put on the table and allowed participants and interviewers to refer back to and build from them. This was apparent in the way P2, in example 2 part 1, after looking at the objects on the table, realized that their previous remarks would not add up to a consistent worldview. In turn, P2 started to imagine what real harmony between humanity and nature would be like.

We have not done a comparative study between the kind of imagining that our final design scaffolded and the kind that would have been scaffolded when only handing participants the original written trends. Whether abstract trends afford imagining might also be a matter of skill: it might be the case for an engineer at Rijkswaterstaat, but not for the average Dutch citizen. At any rate, given the preceding analysis, we think it is plausible that the stories, the social setting and discussion tools tapped into our embodied potential for meaning-making in a way that only the trends would not have been able to do (or at least not for most Dutch citizens).

Our goal with this paper was to show that arranging the social setting and designing the tools have an influence on the kind of imaginative process that can unfold. The three examples help to concretize this view. The participants are not first imagining the future world in their heads and then building this world from the objects on the table. Rather, relations made by tracing the conversation and assigning meaning to objects and the way other participants act in the process become affordances for further imagination. In other words, the imagined future world unfolds in the shared placing, replacing, moving, taking away and talking about the artefacts on the table. Imagination from this perspective can be regarded as a shared and scaffolded activity.

Guided by developments in ecological and enactive philosophy, we have started from the assumption that many intellectual activities are concrete, situated and scaffolded by the socio-material environment. Reflection and engagement are not orthogonal activities, they are rather interdependent. In this instance, the activity of imagination was done by pointing, negotiating, talking, probing and reflecting. Imagination in these examples is in the enactment of affordances. It is in the doing [10]. As Shaun Gallagher puts it "In this respect, the imaginative practice is to manipulate concepts, thoughts, images-take them up and play with them, move them around, in order to solve a problem, or map them onto novel affordance spaces." [10]. The imaginative practice is a social, material and therefore tangible practice, in which design can take part.

\section{CONCLUSION}

In this paper, we have presented a design case for shared imagination. We followed up on a development in embodied cognition that sees 'higher' cognitive activities as situated and embodied, breaking the opposition between skillful coping and detached reasoning. On this view, imagination is not a reflective activity an individual does by herself, but a shared and embodied activity scaffolded by tangible design.

We presented a case study in which we designed a toolkit to facilitate imagining the Netherlands in 2050. We wrote speculative stories of people living in 2050 and designed an assortment of objects. We held several workshops to use the toolkit for shared imagination for Rijkswaterstaat. We finally analyzed how, in the context of the workshops, the stories and objects provided affordances for shared imagination.

This study demonstrates the use of an ecological and enactive approach to imagination in a design project. It shows how imagination can also be regarded as an embodied, engaged and situated 
activity that is scaffolded by a material and social environment. This opens the door for careful exploration of designing for conceptual or intellectual activities, while remaining aligned with the TEI-community's theoretical roots.

\section{ACKNOWLEDGMENTS}

We sincerely thank the reviewers for their helpful comments, Rijkswaterstaat for their collaboration and Tom Djajadiningrat for his guidance on the project and the fruitful discussions we had with him.

\section{REFERENCES}

[1] Alissa N. Antle, Greg Corness, Saskia Bakker, Milena Droumeva, Elise van den Hoven, and Allen Bevans. 2009. Designing to Support Reasoned Imagination through Embodied Metaphor. In Proceedings of the seventh ACM conference on Creativity and Cognition (C\&C '09), 275-284. https://doi.org/10.1145/1640233. 1640275

[2] Jelle Bruineberg and Erik Rietveld. 2014. Self-organization, free energy minimization, and optimal grip on a field of affordances. Frontiers in Human Neuroscience 8. https://doi.org/10.3389/fnhum.2014.00599

[3] Andy Clark and Josefa Toribio. 1994. Doing without representing? Synthese 101, 3: 401-431. https://doi.org/10.1007/BF01063896

[4] Robert W. Clowes and Dina Mendonça. 2016. Representation Redux: Is there still a useful role for representation to play in the context of embodied, dynamicist and situated theories of mind? New Ideas in Psychology 40: 26-47. https://doi.org/ 10.1016/j.newideapsych.2015.03.002

[5] Ludger van Dijk and Erik Rietveld. 2020. Situated imagination. Phenomenology and the Cognitive Sciences. https://doi.org/10.1007/s11097-020-09701-2

[6] Paul Dourish. 2004. Where the Action Is: The Foundations of Embodied Interaction. MIT press, Cambridge, MA.

[7] Hubert Dreyfus. 1992. What Computers Still Can't Do. MIT Press, Cambridge, MA.

[8] Anthony Dunne and Fiona Raby. 2013. Speculative Everything: Design, Fiction, and Social Dreaming. MIT Press, Cambridge, MA.

[9] Lucia Foglia and Rick Grush. 2011. The Limitations of a Purely Enactive (NonRepresentational) Account of Imagery. Fournal of Consciousness Studies 18, 5-6: 35-43.

[10] Shaun Gallagher. 2017. Enactivist Interventions: Rethinking the Mind. Oxford University Press, Oxford, UK.

[11] James Gibson. 1979. The Ecological Approach to Visual Perception.Lawrence Erlbaum Associates Publishers, Hillsdale, NJ.
[12] Lone Koefoed Hansen and Susan Kozel. 2007. Embodied imagination: a hybrid method of designing for intimacy. Digital Creativity 18, 4: 207-220. https://doi. org/10.1080/14626260701743200

[13] Celia B. Harris, Paul G. Keil, John Sutton, and Amanda J. Barnier. 2010. Collaborative remembering: when can remembering with others be beneficial? In ASCS09: proceedings of the 9th Conference of the Australasian Society for Cognitive Science, 131-134. https://doi.org/10.5096/ASCS200921

[14] Caroline Hummels and Jelle van Dijk. 2015. Seven Principles to Design for Embodied Sensemaking. In Proceedings of the Ninth International Conference on Tangible, Embedded, and Embodied Interaction (TEI '15), 21-28. https://doi.org/10.1145/ 2677199.2680577

[15] Tim Ingold. 2011. The Perception of the Environment: Essays on Livelihood, Dwelling and Skill. Routledge, London, UK.

[16] Hiroshi Ishii, Dávid Lakatos, Leonardo Bonanni, and Jean-Baptiste Labrune. 2012. Radical atoms: beyond tangible bits, toward transformable materials. Interactions 19, 1: 38-51. https://doi-org.dianus.libr.tue.nl/10.1145/2065327.2065337

[17] Julian D. Kiverstein and Erik Rietveld. 2018. Reconceiving representation-hungry cognition: an ecological-enactive proposal. Adaptive Behavior 26, 4: 147-163.

[18] Nick Logler, Daisy Yoo, and Batya Friedman. 2018. Metaphor Cards: A Howto-Guide for Making and Using a Generative Metaphorical Design Toolkit. In Proceedings of the 2018 Designing Interactive Systems Conference (DIS '18), 13731386. https://doi.org/10.1145/3196709.3196811

[19] Ine Mols, Elise van den Hoven, and Berry Eggen. 2014. Making memories: a cultural probe study into the remembering of everyday life. In Proceedings of the 8th Nordic Conference on Human-Computer Interaction: Fun, Fast, Foundational, 256-265. https://doi-org.dianus.libr.tue.nl/10.1145/2639189.2639209

[20] Alva Noë. 2012. Varieties of Presence. Harvard University Press, Cambridge, MA.

[21] Donald A. Norman. 1988. The Psychology of Everyday Things. Basic Books, New York, NY, US.

[22] Donald A. Norman. 1999. Affordance, conventions, and design. Interactions 6, 3: 38-43. https://doi.org/10.1145/301153.301168

[23] Donald A. Norman. 2008. THE WAY I SEE IT - Signifiers, not affordances. interactions 15, 6: 18. https://doi.org/10.1145/1409040.1409044

[24] Erik Rietveld. 2008. Situated Normativity: The Normative Aspect of Embodied Cognition in Unreflective Action. Mind 117, 468: 973-1001. https://doi.org/10. 1093/mind/fzn050

[25] Erik Rietveld and Julian Kiverstein. 2014. A Rich Landscape of Affordances. Ecological Psychology 26, 4: 325-352. https://doi.org/10.1080/10407413.2014.958035

[26] Rijkswaterstaat. 2020. Verkenningen: Dwarsdoorsnede van Nederland. Retrieved from https://www.expeditierws2050.nl/home/dwarsdoorsnede-van-nederland/

[27] Zuzanna Rucińska. 2014. Basic Pretending as Sensorimotor Engagement? In Contemporary Sensorimotor Theory (Studies in Applied Philosophy, Epistemology and Rational Ethics), 175-187. https://doi.org/10.1007/978-3-319-05107-9_12

[28] Brygg Ullmer, Orit Shaer, Ali Mazalek, and Caroline Hummels. 2020 (forthcoming). Weaving Fire into Form: Aspirations for Tangible and Embodied Interaction. 